\title{
INTERSYSTEM INTERFERENCE DUE TO HYDROMETEOR SCATTERING ON SATELLITE DOWNLINK SIGNALS IN TROPICAL LOCATIONS
}

\author{
Ajewole M.O. and Ojo, J.S. \\ Department of Physics, Federal University of Technology, P. M. B. 704, Akure, Nigeria
}

\begin{abstract}
This paper computes intersystem interference due to scattering by hydrometeors into the downlink receiver terminal of a communication satellite in three tropical locations, Ile-Ife (Nigeria), Nairobi (Kenya) and Douala (Cameroon). The evaluation procedure used was the simplified 3-D bistatic radar equation and the exponential rain-cell model. The results obtained in this study show that the cumulative distribution of effective transmission loss $\left(L_{e}\right)$ is much lower than the cumulative distribution of transmission loss in all the locations. For instance, at time percentage unavailability of $0.01 \%$, the effective transmission loss is lower than the transmission loss by $20 \mathrm{~dB}$ in Douala, $15 \mathrm{~dB}$ at Ile-Ife and $11 \mathrm{~dB}$ in Nairobi. The lower the effective transmission loss, the higher is the interference in the satellite receiver. Also, a comparison of the effective transmission loss in the regions shows that Douala has the worst effective transmission loss, that is, highest interference at all frequencies and time percentages. Therefore, while it is acknowledged that satellite fade outs at frequencies greater than $10 \mathrm{GHz}$ is a problem in these locations, it may be deduced that Douala has comparatively the highest frequency of outages.
\end{abstract}

KEY WORDS: Hydrometeor scatter, intersystem interference, effective transmission loss, satellite system, microwave system, rain attenuation

\section{INTRODUCTION}

The use of communication satellites to provide new telecommunication services and to expand existing ones continues to receive international support and patronage. Integrated services digital networks (ISDN) connection via satellite for telephoning and data communication, internet services relying on very small aperture terminal (VSAT) systems, satellite television, remote sensing of the environment and so on are typical services which depend on satellite communication for reliable and efficient service delivery. In Sub-Saharan Africa, these services are still evolving and if well managed, have the potential to assist the region to catch up with modern information age. Many of the communication satellites in use operate at frequencies, which are at the same time being used to provide other terrestrial telecommunication services such as terrestrial telephoning and television broadcast. This has brought about phenomenal amount of pressure on the available bandwidth thus leading to bandwidth congestion at the lower frequencies. Moving to the higher frequencies greater or equal to $10 \mathrm{GHz}$ to gain some bandwidth has been at some cost to the quality of the wanted satellite channel. As frequency becomes higher, signal degradation due to interaction with hydrometeors also becomes stronger. Hydrometeor induced signal attenuation and scattering, signal depolarization, intersystem interference could become very strong at frequencies higher than $10 \mathrm{GHz}$. For example rain scattering is severe at these frequencies, because the size of the raindrop is comparable to the wavelength of the signal. Also atmospheric gases, that is, dry air (oxygen) and water vapour have a combined strong specific attenuation in the frequency window 22.2-30 GHz (ITU-R, P. 676-5, 2003). When the common volume formed by the intersection of the terrestrial and satellite signals lay in the bright band (melting layer), reflectivity decreases at the rate of $6.5 \mathrm{~dB} /$ $\mathrm{km}$ in this region leading to strong ice scattering and attenuation of the satellite channel. A weak satellite signal at the reception point is susceptible to severe interference from a strong terrestrial system operating in its neighbourhood at the same frequency if their beam centers intersect and contain precipitating particles. Many options of interference geometries are possible. 
This paper considers a situation in which a satellite down link signal is interfered by the signal from a terrestrial microwave network operating at the same frequency as the satellite system. When this happens, there is usually a decrease in the signal-to-noise ratio at the satellite terminal as a result of energy re-directed in the forward direction into its receiving antenna system.

The evaluation of the received interference power is important for the design of microwave communication systems. Several attempts have been made in the past to quantify interference levels either by the direct measurement or by simulation. Among such efforts are Crane, (1974), Awaka, (1989), Olsen et al., (1993), Holt et al., (1993), and Capsoni and D'Amico, (1997). The efforts yielded good results in the temperate regions. In the tropical regions, very limited efforts have been made to address this problem. Ajewole et al., (1999a) and Ajewole (2003) studied the problem using radio-climatological data from Nigeria to predict interference levels on propagation paths in Nigeria.

Despite the large volume of work already carried out on the subject in temperate regions, the results obtained in such studies are always inadequate on tropical paths. This is because the nature and characteristics of tropical rainfall are occasionally different from those of the temperate rainfall. For instance, tropical rainfall is most often convective, is characterized by large raindrop sizes, is of high intensity and often times accompanied by severe lightning and thunderstorm. If a convective rain cell passes over the common volume formed by the intersecting beams of a satellite downlink antenna and a terrestrial microwave relay system, interference will be received in the satellite system so long as the frequencies are the same. Further, the satellite signal suffers additional rain attenuation (Figure 1) on its path hence, the statistics of the transmission loss alone will not be sufficient to predict the interference received by the wanted satellite channel. This additional attenuation has the potential to further reduce the signal-to-noise ratio at the satellite terminal. Thus the additional attenuation is the basis of the evaluation of the effective transmission loss on the path, and whenever it becomes larger than the link margin may result in the total outage of the satellite channel no matter the interference levels received from the terrestrial system. It is therefore important to consider this extra attenuation of the wanted signal in the analysis of intersystem interference, if the correct interference levels are to be determined for the purpose of better planning and design of microwave communication systems in these locations.

\section{Wanted satellite signal}

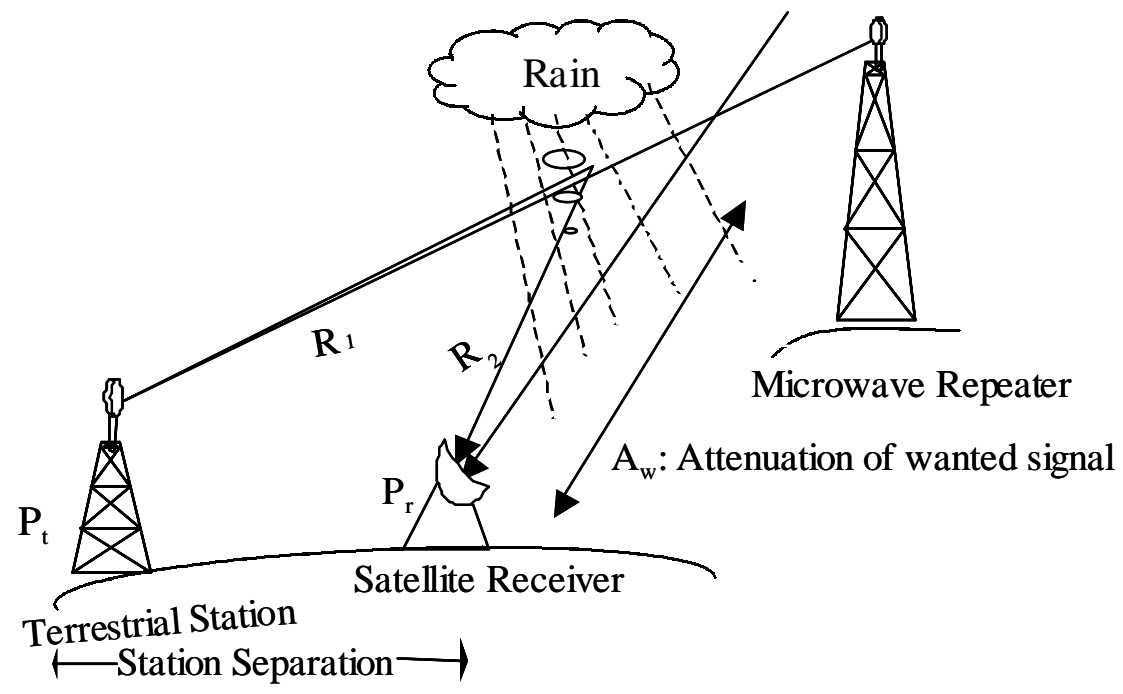

Figure 1: Attenuation of wanted signal 
The present study investigates hydrometeor scattering in additional locations in the equatorial belt of Africa; Douala- Cameroon $\left(9.70^{\circ} \mathrm{E}, 4.05^{\circ} \mathrm{N}\right)$, and Nairobi- Kenya $\left(36.75^{\circ} \mathrm{E}, 1.30^{\circ} \mathrm{S}\right)$. The study then computes interference in the locations in terms of the effective transmission loss and compares the results obtained with Ile-Ife, Nigeria $\left(4.34^{\circ} \mathrm{E}, 7.33^{\circ} \mathrm{N}\right)$.

\section{THEORETICAL CONSIDERATIONS AND INPUTPARAMETERS}

The effective transmission loss is defined as the transmission loss minus the extra attenuation suffered by the wanted signal (Capsoni and D'Amico, 1997). It is usually evaluated on the basis of a joint and conditioned statistics of the transmission loss and the extra attenuation. It is therefore expressed as

$$
L_{e}=L-A_{w}=P_{t}-\left(P_{r}+A_{w}\right)
$$

$L$ is the transmission loss defined as the ratio of the interfering transmitted power $P_{t}$ to the interfering received power $P_{r}$ at the interfered station, and is evaluated using the Bistatic Radar Equation (BRE). $A_{w}$ is the extra attenuation on the wanted signal. Using the simplified form of the BRE (Capsoni et al., 1992), the transmission loss is expressed as

$$
L=10 \log \frac{P_{t}}{P_{r}}
$$

where

$$
\frac{P_{r}}{P_{t}}=\frac{A_{t}\left(R_{1}\right) A_{r}\left(R_{2}\right) A_{g} G_{t} G_{r} \lambda^{2} \sigma_{b i}}{(4 \pi)^{3}} \times C V
$$

and the term $\mathrm{CV}$ which denotes the common volume formed by the interfering beams which is evaluated from the following integral

$$
C V=\int_{0}^{\infty} \frac{F_{t}\left(\vartheta_{1}, \phi_{1}\right) F_{r}\left(\vartheta_{2}, \phi_{2}\right)}{R_{1}^{2} R_{2}^{2}} d V
$$

From equations (2.3) and (2.4) and Figure 1, $A_{t}\left(R_{1}\right)$ and $A_{r}\left(R_{2}\right)$ are the attenuations along the paths $R_{1}$ from the transmitter to the common volume, and $R_{2}$ from the common volume to the satellite receiver. $A_{g}$ is the attenuation due to gaseous absorption. $G_{t}$ and $G_{r}$ are the transmitter and receiver antenna gains, and $\lambda$ is the wavelength of the radio signal. The quantities $F_{t}\left(\vartheta_{1}, \phi_{1}\right)$ and $F_{r}\left(\vartheta_{2}, \phi_{2}\right)$ represents the directivity function of the transmitting and receiving antenna systems, and are calculated in terms of their effective area. $\sigma_{b i}$ is the bistatic scattering cross section which is defined as the scattering cross section per unit volume of precipitation. It is related to the radar reflectivity factor $Z$ and the point rain rate $R$ as $Z=10 \log z$, where $z=a R^{b}$. In this study, we assumed the tropical lognormal raindrops size distribution of Ajayi and Olsen (1985), and since the distribution fits the convective thunderstorm rain type very well, we have assumed the $Z-R$ relationship proposed by Ajayi and Owolabi, (1987) for tropical thunderstorm rain in the study in which $a=461$ and $b=1.31$ respectively.

This study covers the frequency range 4-35 GHz used presently by most service providers for terrestrial and Earth-space communications. The mean annual cumulative distribution of point rain rate $P(R)$ measured at the three locations are used to predict interference levels with the probability of occurrence ranging from $1-10^{-3} \%$.

The attenuation of the signals due to rain was evaluated using the Power law relationship between attenuation and rain rate, while attenuation due to atmospheric gases was calculated using the ITU-R Rec. 676-3 (1997). The parameters of the power law relationship for attenuation by thunderstorm rain valid for tropical locations employed in the study are shown in Table 1 for vertically polarized signals only.

Table 1: Regression parameters $k$ and $\alpha$ of the power law expression for thunderstorm rain type (Ajewole et al., 1999b), where $v$ represents vertical polarization states

\begin{tabular}{|cll|}
\hline Freq. (GHz) & \multicolumn{1}{c}{$k_{v}$} & \multicolumn{1}{c|}{$\alpha_{v}$} \\
\hline 4.0 & $6.32 \times 10^{-4}$ & 1.0197 \\
6.0 & $2.61 \times 10^{-3}$ & 1.0656 \\
8.0 & $7.36 \times 10^{-3}$ & 1.117 \\
10.0 & 0.0152 & 1.1297 \\
12.0 & 0.0258 & 1.112 \\
16.0 & 0.05963 & 1.06851 \\
20.0 & 0.834 & 1.03 \\
34.8 & 0.25639 & 0.9903 \\
\hline
\end{tabular}


The rainfall environment itself was modeled in terms of the vertical and horizontal distribution of rain rates. The vertical structure assumes that the rain rate from a point on the ground is constant up to the zero degrees isotherm height, which is equal to the freezing height in the tropical region. Beyond this region, $R(x, y)$ decreases at the rate of $6.5 \mathrm{~dB} / \mathrm{km}$ (ITU-R, Rec. P. 452-11, 2003). The horizontal structure on the other hand assumes that rain rates are exponentially distributed with peak intensity inside the rain cells. This is expressed as (Capsoni et al., 1987)

$$
R(x, y)=R_{M} e^{-\frac{r}{r_{0}}}
$$

The study also assumes the expression proposed by Capsoni et al., (1987) for the characteristic distance from the rain cell centre $r_{0}(\mathrm{~km})$ over which the rain rate decreases to $\exp (-1)$ of its value, the retrieval algorithm proposed for the number density of rain cells, and the power law dependence of the local cumulative distribution of point rate at the location which is expressed as

$$
P(R)=P_{0}\left(\ln \frac{R^{\prime}}{R}\right)^{k} \quad 0<R<R^{\prime}
$$

$P_{0}$ and $k$ are constants which are evaluated using least squares fitting technique and $R^{\prime}(\mathrm{mm} / \mathrm{h})$ is assumed to be about four times the highest rain rate measured at the location.

The study utilized the cumulative distribution of the measured rain rates at Ile-Ife, Douala, and Nairobi to investigate the effective transmission loss in these locations (McCarthy et al., 1994 a, b, c). The summary of $P_{0}, R^{\prime}$ and $k$ for Ile-Ife, Nigeria, Nairobi, Kenya and Douala, Cameroon is shown in Table 2. An average water vapor density of $20 \mathrm{~g} / \mathrm{m}^{3}$ was assumed in the study (ITUR Rec. P. 836-1, 1997). In the evaluation of the interference levels, we considered the worst case of coupling, which occurs whenever the transmitting and receiving systems are both vertically polarized (Awaka and Oguchi, 1982).

The detailed description of the equations for calculating the transmission loss is omitted here, but can be found from any of these references (Capsoni and D'Amico, 1997; Awaka, 1989; COST Project 210, 1991; Ajewole et al., 1999a; Ajewole, 2003).
Table 2: Power law parameters (eqn. (2.6)) for the local cumulative probability density for thunderstorm rain type for the locations considered and the $Z-R$ relation

\begin{tabular}{|l|lll|}
\hline \multirow{2}{*}{ Location } & \multicolumn{4}{|c|}{$Z=461 R^{1.31}$} \\
& $P_{0}$ & $R^{\prime}$ \\
\hline Ile-Ife, Nigeria & $5.91 \times 10^{-4}$ & 624 & 4.5585 \\
Nairobi, Kenya & $4.727 \times 10^{-4}$ & 400 & 4.7754 \\
Douala, Cameroon & $2.237 \times 10^{-4}$ & 732 & 5.9737 \\
\hline
\end{tabular}

\section{Evaluation Procedure and Additional Input Parameters Used}

The interfering terrestrial microwave system is a low elevation angle type, usually of about $1^{\circ}$ elevation angle, having a beamwidth of $1.6^{\circ}$ and gain of $45 \mathrm{~dB}$. The satellite terminal, which is the station receiving interference, is assumed to have a narrow beamwidth of $0.18^{\circ}$ and a gain of $59 \mathrm{~dB}$. We also assumed a satellite elevation angle of $55^{\circ}$ in the locations. This elevation angle is used for most of the tele-traffic over the Atlantic Ocean in Nigeria. Frequencies ranging from $4-34.8 \mathrm{GHz}$ are assumed. A mean freezing height, which varies from $4.54 \mathrm{~km}$ in the South to $4.79 \mathrm{~km}$ in the North in Nigeria is assumed for Cameroon and Kenya. This is because the measured data are not available in these other locations. Further, according to ITU-R Rec. P. 839-3 (2001) $h_{F R}$ is $5 \mathrm{~km}$ for stations located at latitudes between $0 \leq \varphi \leq 23$ and $0 \geq \varphi \geq-210^{\circ}$ and $23^{\circ}$, and since the stations are located within this latitudinal space and because the ITU-R value overestimates $h_{F R}$, the values for Nigeria are also assumed. The path geometries used in the study are shown in Table 3.

Table 3: Geometrical parameters for calculating

\begin{tabular}{|c|c|c|c|c|}
\hline$R_{1}, \mathrm{~km}$ & $T x-R x$ Dist., $k m$ & $R_{2}, k m$ & ${ }^{*} \mathrm{CV}$ height, $\mathrm{km}$ & ${ }^{*} \mathrm{CV}$ length, $\mathrm{km}$ \\
\hline 50.0 & 50.7 & 1.245 & 0.711 & 1.021 \\
\hline 100.0 & 101.6 & 2.849 & 1.62 & 2.343 \\
\hline 150.0 & 152.7 & 4.810 & 2.725 & 3.966 \\
\hline 200.0 & 204.0 & 7.135 & 4.022 & 5.893 \\
\hline 250.0 & 255.4 & 9.812 & 5.507 & 8.121 \\
\hline
\end{tabular}
transmission loss

$* C V$ - Common Volume, $T x-R x$ distance refers to the distance between transmitter and the receiver, while $R_{1}$ and $R_{2}$ are as defined in Figure 1 


\section{RESULTS AND DISCUSSION}

The simplified form of the bistatic radar equation (Capsoni et al., 1992) and the exponential rain cell model of Capsoni et al., (1987) are used to predict the effective transmission loss, $L_{e}$, for propagation paths in Douala, Nairobi and IleIfe. In Figure 2 we compare $L_{e}$ with the transmission loss, $L$, statistics at a frequency of $16 \mathrm{GHz}$ for varying time percentage unavailability in these locations. The results are for a satellite elevation angle $55^{\circ}$ of and for propagation path length of $50 \mathrm{~km}$ from the terrestrial antenna to the common volume. The terrestrial antenna gain is assumed to be $45 \mathrm{~dB}$. The results show that $L$ decreases with increasing percentage time unavailability while $L$ statistics are fairly constant in the three locations. For a time availability of $99.99 \%$ (0.01\% time unavailability), a difference of about $20 \mathrm{~dB}$ is noticeable between $L_{e}$ and $L$ statistics in Douala, it is about $11 \mathrm{~dB}$ in Nairobi and about $15 \mathrm{~dB}$ at Ile-Ife. Using the results at IleIfe as the basis for comparison, Figure 2 further shows that for time unavailability of $0.01 \%, L_{e}$ in Douala is worse than at Ile-Ife by about $9 \mathrm{~dB}$, while it is better in Nairobi than Ile-Ife by about $4 \mathrm{~dB}$ at $16 \mathrm{GHz}$. The results also show that these differences decrease with increasing outage time.

Figure 3 shows the results of the variation of $L_{e}$ with percentage time unavailability at frequencies of 4,16 and $20 \mathrm{GHz}$. The propagation path length from the terrestrial antenna to the common volume is $50 \mathrm{~km}$. The results show that $L_{e}$ increases as outage time (\% time probability) increases. The $L_{e}$ is consistently poor at high frequencies in Douala. The results of the variation of $L_{e}$ with terrestrial antenna distance to the common volume are shown in Figure 4 for a frequency of $16 \mathrm{GHz}$, TS-CV distance of 50 - $150 \mathrm{~km}$ for ease of presentation and percentage probabilities ranging from $0.001 \%$ to $0.1 \%$. Generally speaking, $L_{e}$ increased with increasing terrestrial (TS) to common volume $(\mathrm{CV})$ distance (or terrestrial to satellite antenna separations, $T x-R x$ ). At TS-CV distance of $50 \mathrm{~km}$ $(T x-R x$ of $50.7 \mathrm{~km})$ and time probability of $0.01 \%, L_{e}$ is about $110 \mathrm{~dB}, 114 \mathrm{~dB}$ and $102 \mathrm{~dB}$ respectively at Ile-Ife, Nairobi and Douala. At the time percentage of 0.001, the values are down to $99.3 \mathrm{~dB}, 106.3 \mathrm{~dB}$ and $85.3 \mathrm{~dB}$ for these locations.

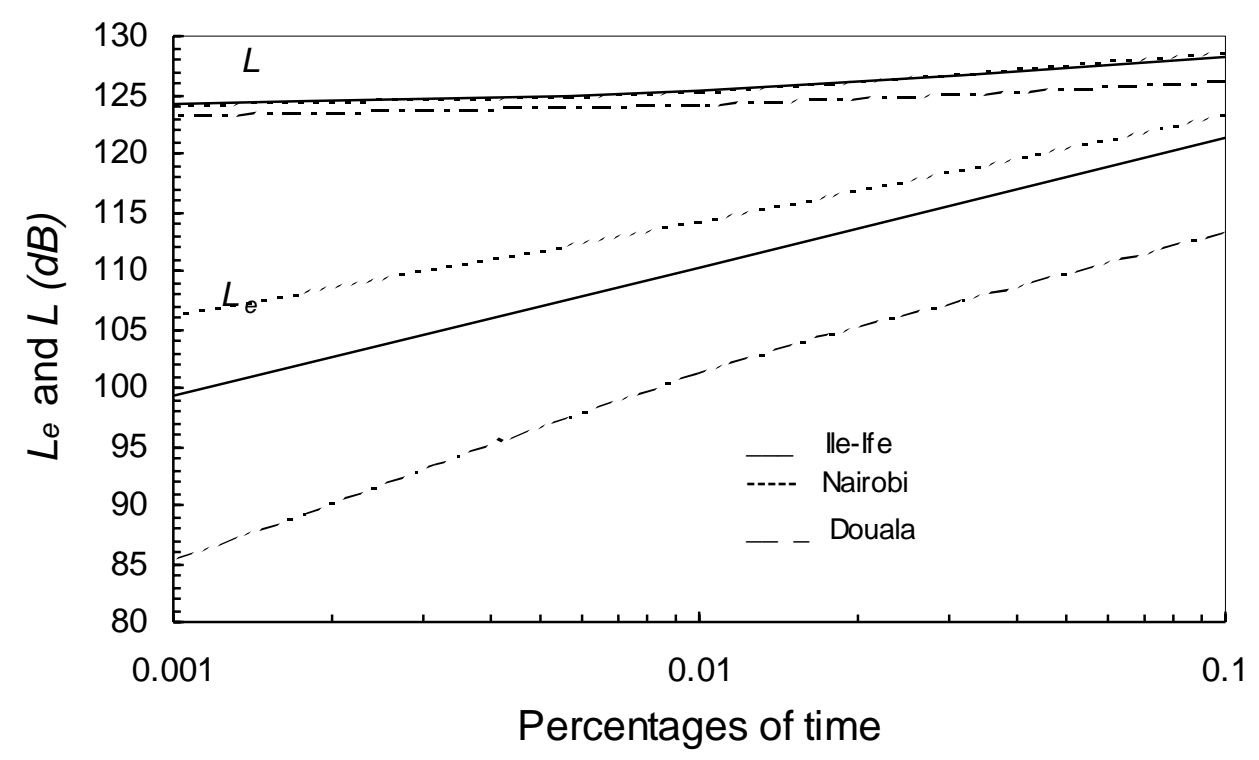

Figure 2: Comparison of the effective transmission loss and the transmission loss for a frequency of 16 GHz, path length of $50 \mathrm{~km}$ from terrestrial antenna to the common volume, elevation angle of $55^{\circ}$ at some percentage times 


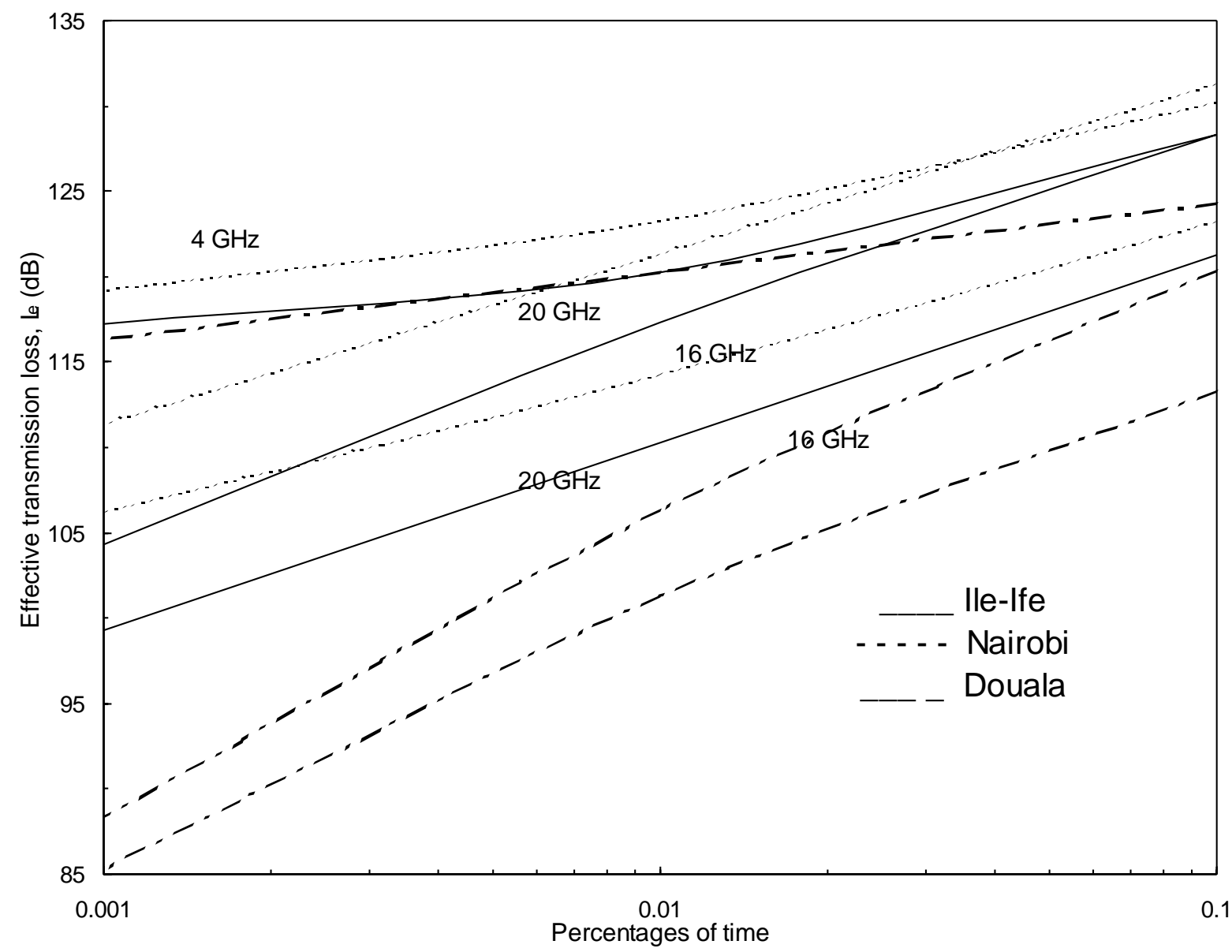

Figure 3: Variation of effective transmission loss with percentage time probability at frequencies of 4,16 , and $20 \mathrm{GHz}$ for a distance of $50 \mathrm{~km}$ from the terrestrial antenna to the common volume and path elevation of $5^{\circ}$.

The effective transmission loss, $L_{e}$, is lowest in Douala, and highest in Nairobi for the percentage times considered. It is obvious from the results that as the distance from the TS-CV increases, $L$ increases. This means that the shorter the TS-CV (the closer the stations), the higher is the interference received in the satellite channel since the interfering signal arrives weakerdue to its increased path attenuation. The higher interference levels in Douala are a consequence of the higher rain attenuation of the wanted signal arising from the higher probability of occurrence of convective andhigher intensity rainfall in that region. According to McCarthy et al., (1994a - c), the annual rain water accumulation in these locations are $1400 \mathrm{~mm}$ at IleIfe is $4000 \mathrm{~mm}$ at Douala and $900 \mathrm{~mm}$ in Nairobi. At TS-CV distances lower than $200 \mathrm{~km}$, there is a clear dependence of $L_{e}$ on the local cumulative distribution of point rain rate. At larger distances, this dependence disappears. Further, the possibility of system collapse or outage due to additional attenuation on the wanted path is stronger in Douala (Cameroon) than at the other locations. 


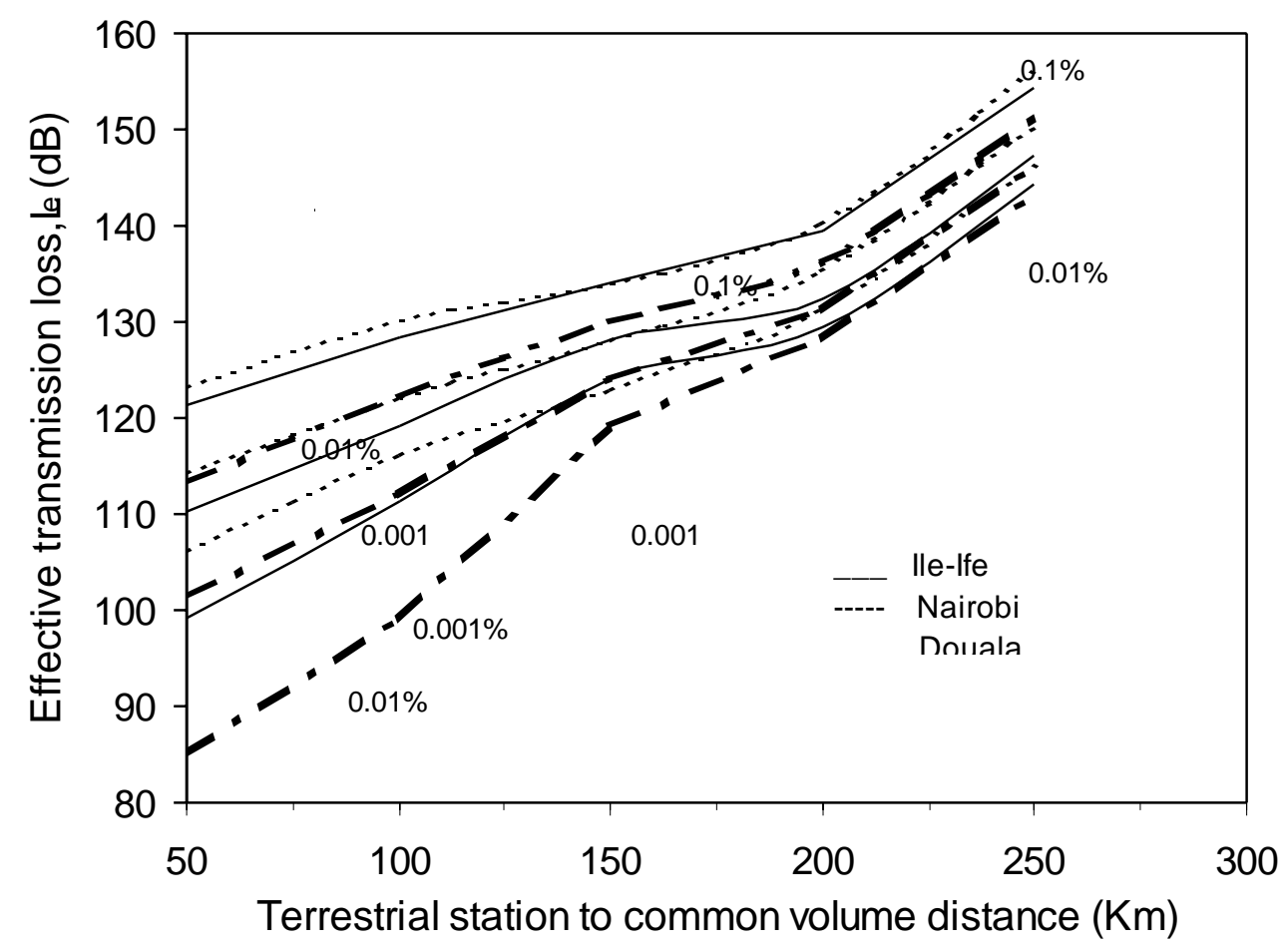

Figure 4: Comparison of the effective transmission loss for varying terrestrial system-to-common volume distance for Ile-Ife, Nairobi and Douala at some $\%$ of times, frequency of $16 \mathrm{GHz}$ and satellite station of elevation of $55^{\circ}$

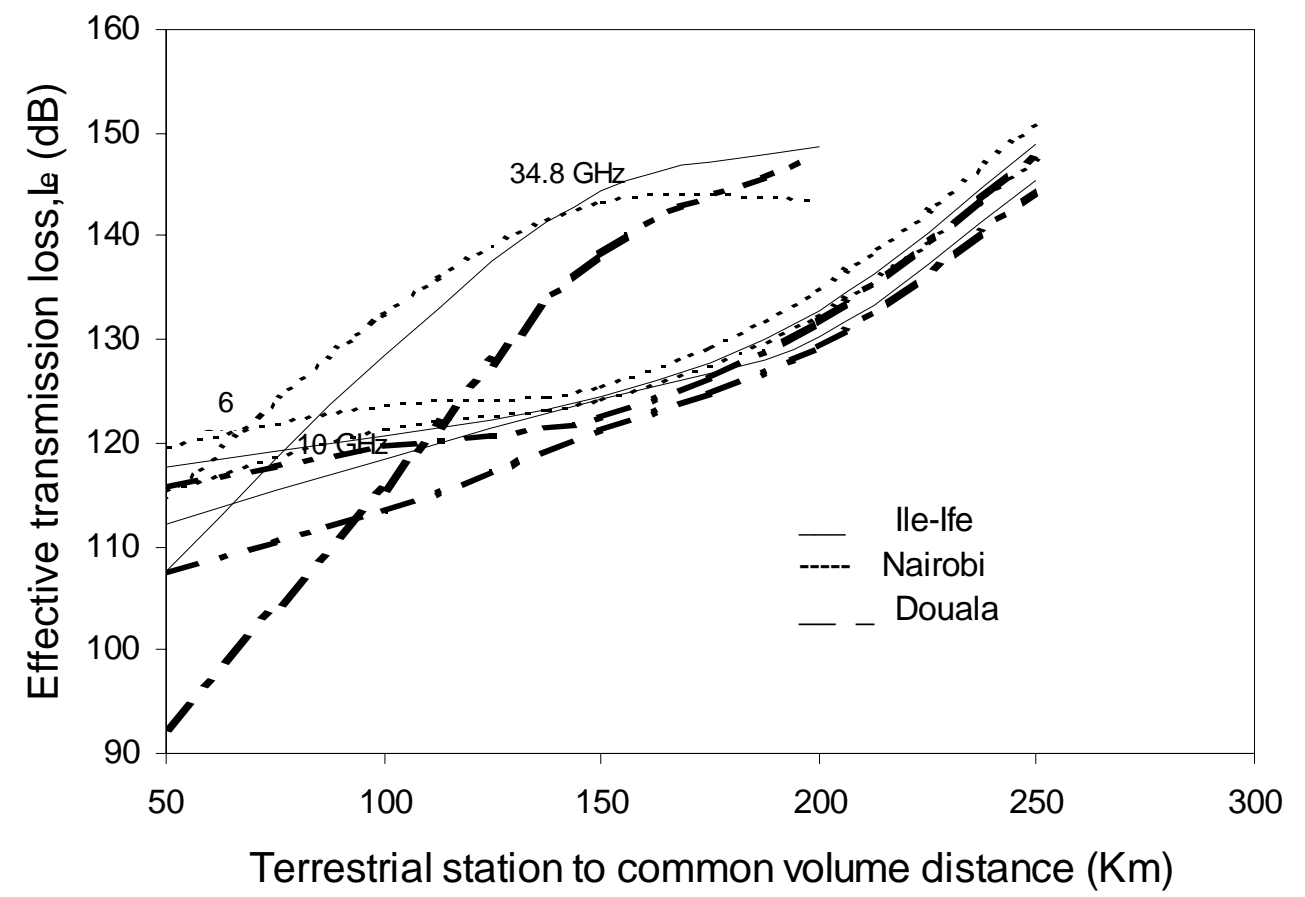

Figure 5: Comparison of the effective transmission loss with terrestrial antenna to common volume distance for Ile-Ife, Nairobi and Douala at some frequencies, $0.01 \%$ of time, satellite station elevation angle of $55^{\circ}$ and terrestrial gain of $45 \mathrm{~dB}$ 
In Figure 5, also shows the variation of effective transmission loss with terrestrial to common volume distances at frequencies of 6,10 and $34.8 \mathrm{GHz}$ for exceedance probability of $0.01 \%$ of time (a probability used for most practical considerations). The result, though truncated at TS-CV distance of $150 \mathrm{~km}$ in the figure for convenience, shows that at frequencies lower than 34.8 $\mathrm{GHz}, L_{e}$ is bounded in a narrow range, while it shows tendency for saturation at TS-CV distances greater than about $150 \mathrm{~km}$ at $34.8 \mathrm{GHz}$. Further, at a distance of about $50 \mathrm{~km}$ and frequency of $34.8 \mathrm{GHz}$, the difference between $L_{e}$ in Douala and Nairobi is about $22 \mathrm{~dB}$. This difference decreases as the distance between the TS-CV increases. At the low frequencies and shorter TS-CV, the difference is about $8 \mathrm{~dB}$. Regardless of the transmitting frequency, $L_{e}$ is lower in Douala compared to the other locations in this study, which means that there will be stronger interference effect on propagation paths in Cameroon.

Figures 6 (a) and (b) show the comparison of the frequency characteristics of $L_{e}$ at some percentage exceedance times for short and long propagation path lengths. Generally, at short path lengths, $L_{e}$ decreases with increasing frequency except at the frequency window of $16-20 \mathrm{GHz}$ where there is a slight increase. At longer path lengths and frequencies higher than $16 \mathrm{GHz}$, the strong decrease in the radar reflectivity factor plays a dominant role. This can be viewed from the fact that the common volume at this distance is in the ice region, $5.51 \mathrm{~km}$. Therefore, ice scattering predominates over rain scattering for a common volume located in the ice region. Thus, the transmission losses are consistently higher than at the lower TS-CV distances where the common volumes are located in the rain region.

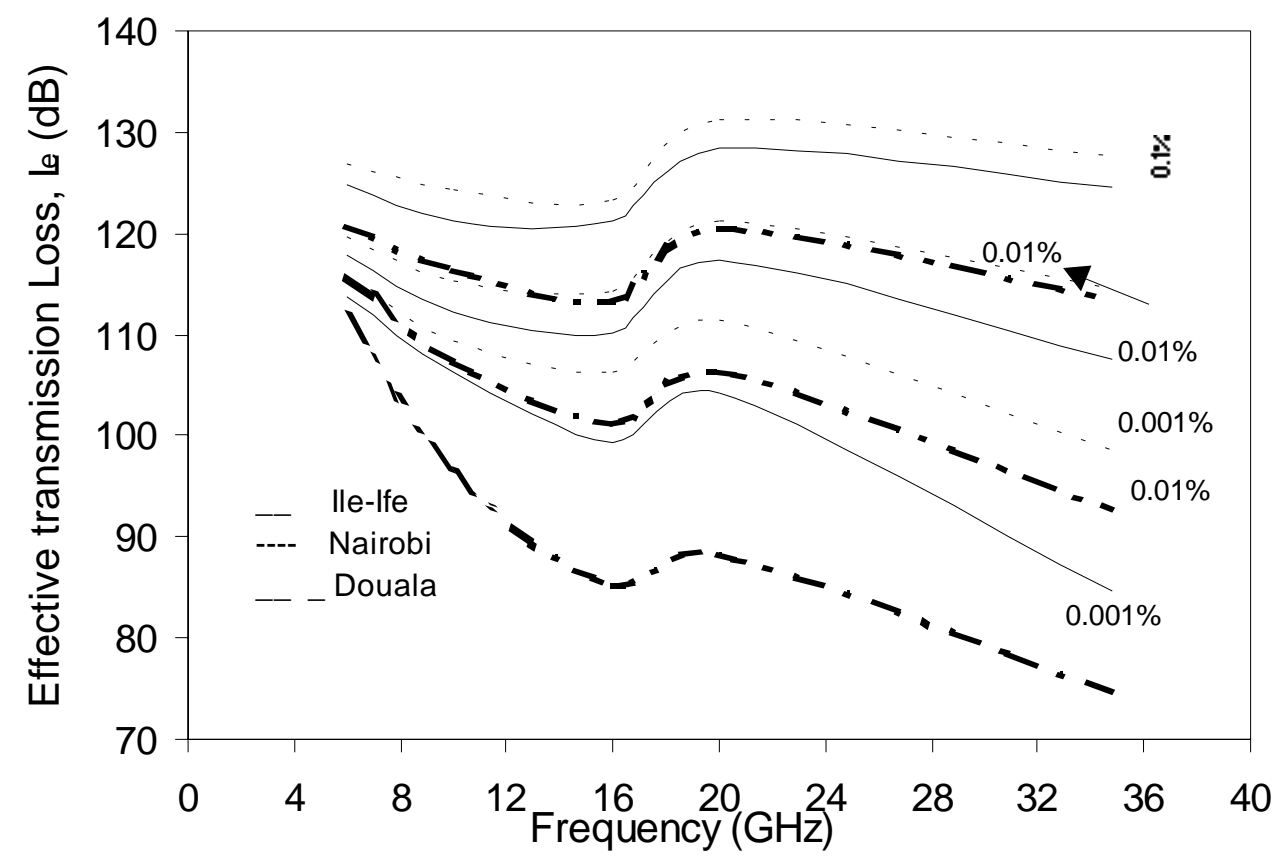

Figure 6a: Comparison of the frequency characteristics of the effective transmission loss for Ile-Ife, Nairobi and Douala at some \% of time, TS-CV distance of $50 \mathrm{Km}$ (short path length) and satellite station elevation of $55^{\circ}$ 


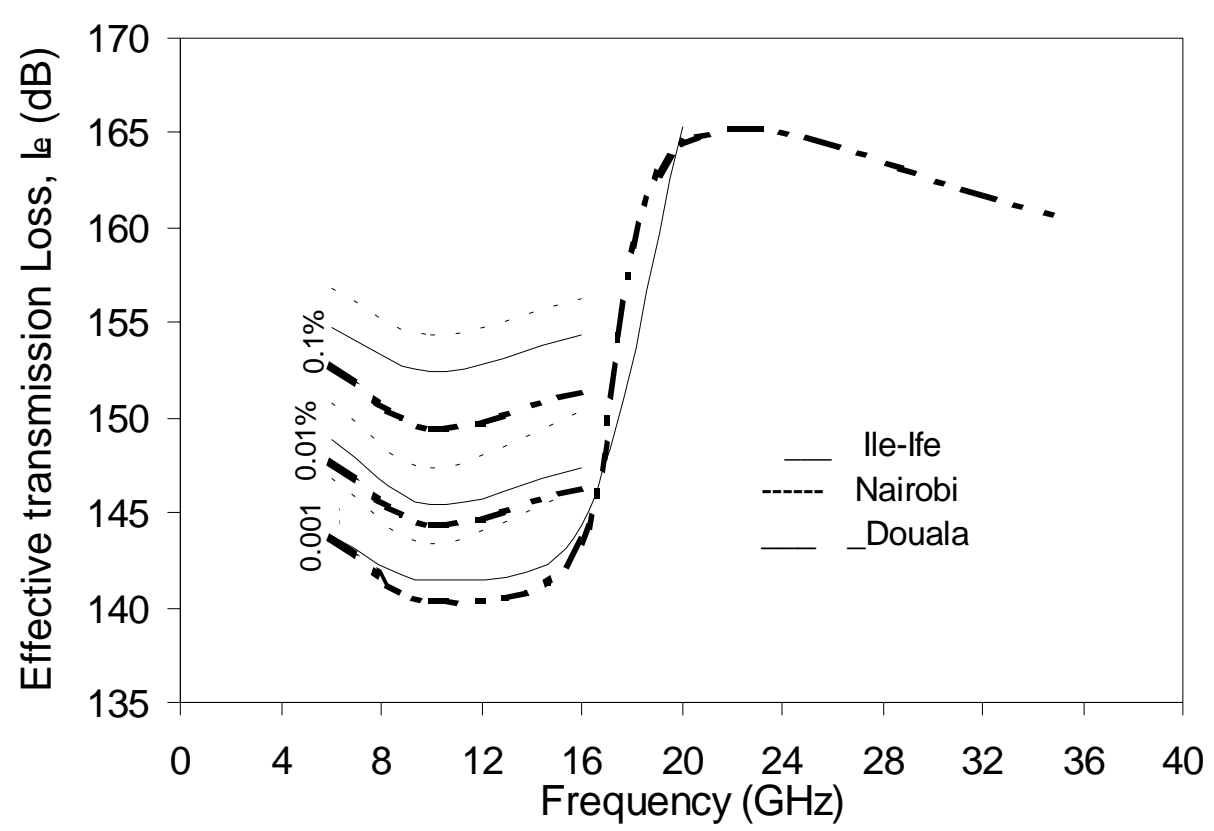

Figure 6b: Comparison of the frequency characteristics of the effective transmission loss for Ile-Ife, Nairobi and Douala at some \% of time, TS-CV distance of $250 \mathrm{Km}$ (long path length) and satellite station elevation of $55^{\circ}$.

\section{CONCLUSIONS}

This study has investigated bistatic interference on satellite communication systems in low latitude tropical regions. Results are presented for a satellite downlink terminal receiving interference from a terrestrial microwave system operating at the same frequency. Short and long path geometries and varying operating frequencies are considered to compute effective transmission loss $L_{e}$ for the prediction of interference in the satellite channel in Douala, Nairobi and Ile-Ife. The results obtained show that intersystem interference computed on the basis of the additional attenuation of the satellite signal is a better indicator of the interference levels received in the locations. Further, intersystem interference will be more severe in Cameroon than in Nigeria and Kenya. Also, system outages may be a frequent problem in these locations whenever a convective rainstorm intercepts the signal paths.

\section{ACKNOWLEDGEMENTS}

MOA is grateful to the Swedish International Development Agency (SIDA) and the International Centre for Theoretical Physics (ICTP), Trieste, Italy for travel support and the facilities used in the final preparation of the paper. MOA is also grateful to the Federal University of Technology, Akure for research visit to Italy.

\section{REFERENCES}

Ajayi, G. O. and R. L. Olsen (1985): Modeling of a tropical raindrop size distribution for microwave and millimeter wave applications, Radio Sci., 20 (20), 193-202.

Ajayi, G. O. and I. E. Owolabi (1987): Rainfall parameters from disdrometer dropsize measurements at a tropical station, Ann. Telecomm., 42(1-2), 3-12.

Ajewole, M. O. (2003): Bistatic interference due to tropical rainfall types: a comparison of rain-cell models, Atti della Fondazione Giorgio Ronchi, 58 (1), 121-141.

Ajewole, M. O., L. B. Kolawole and G. O. Ajayi (1999a): Evaluation of bistatic intersystem interference due to scattering by hydrometeors on tropical paths, Int. J. Satell. Commun., 17, 337-356.

Ajewole, M. O., L. B. Kolawole, G. O. Ajayi (1999b): Theoretical study of the effect of different types of tropical rainfall on microwave and millimeter propagation, Radio Sci.,34 (5), 1103-1124.

Awaka, J. (1989): A 3D rain cell model for the study of interference due to hydrometeor scattering, J. Comm. Res. Lab., 36 (147), 13-44.

Awaka, J. and T. Oguchi (1982): Bistatic radar reflectivities of Pruppacher-and-Pitter form rain drops at $34.8 \mathrm{GHz}$, Radio Sci., 17(1), 269-278.

Capsoni, C. and M. D'Amico (1997): A physically based simple prediction method for scattering interference, Radio Sci.32(2), 397-407. 
Capsoni, C., F. Fedi, C. Magistroni, A. Paraboni and A. Pawlina (1987): Data and theory for a new model of the horizontal structure of rain cells for propagation applications, Radio Sci., 22(3) 395-404.

Capsoni, C., M. D’Amico, A. Martellucci, L. Ordano and A. Paraboni (1992): A prediction method of scattering interference: Complete procedure versus pencil beam approximate, Proc., URSI Comm. F. Open Symp. On Wave Propagation and Remote Sensing, Ravenscar, UK, 5.3.1-5.3.6.

Commission of the European Communities on Cooperation in the Fields of Scientific and Technical Research, COST PROJECT 210 (1991): Influence of the atmosphere on interference between radio communication systems at frequencies above $1 \mathrm{GHz}$, Final Rept. EUR 13407EN, Brussels.

Crane, R. (1974): Bistatic scatter from rain, IEEE Trans. Antenna and Propagat. AP 22(2), 12-320.

Holt, H., R. McGuinness, D. G. Charlton, P. T. Thompson and M. J. Mehler (1993): The development of a model to estimate the bistatic transmission loss associated with intersystem interference, IEEE Trans. Antennas and Propagat. AP 41(10), 1442-1431.

International Telecommunication Union-Radio Communication Bureau, Rec. P. 676-5 (2003): Attenuation by atmospheric gases in the frequency range $1-350 \mathrm{GHz}$.

International Telecommunication Union-Radio Communication Bureau, Rec. P. 839-3 (2001): Rain height model for prediction methods.
International Telecommunication Union-Radio Communication Bureau, Rec. P. 452-11 (2003): Prediction procedure for the evaluation of microwave interference between stations on the surface of the earth at frequencies above $0.7 \mathrm{GHz}$.

International Telecommunication Union-Radio Communication Bureau, Rec. P. 838-2 (2003): Specific attenuation model for rain for use in prediction models.

McCarthy, D. K., J. E. Allnutt, W. E. Salazar, E. C. Omeata, B. R. Owolabi, T. Oladiran, E. B. Ojeba, G. O. Ajayi, T. I. Raji and C. Zacks (1994a): Results of $11.6 \mathrm{GHz}$ radiometric experiment in Nigeria: Second year, Electron. Lett., 30(17), 1452-1453.

McCarthy, D. K., J. E. Allnutt, W. E. Salazar, F. Wanmi, M. Tchinda, T. D. G. Ndinayi and C. Zacks (1994b): Results of $11.6 \mathrm{GHz}$ radiometric experiment in Cameroon: Second year, Electron. Lett., 30(17), 14491450.

McCarthy, D. K., J. E. Allnutt, W. E. Salazar, R. W. Sitati, M. Okoth, M. J. Mutungi, C. D. Odhiambo and C. Zacks (1994c): Results of $11.6 \mathrm{GHz}$ radiometric experiment in Kenya: Second year, Electron. Lett., 30(17), 14501451.

Olsen R. L., D. V. Rogers, R. A. Hulays, and M. M. Z. Kharadly (1993): Interference due to hydrometeor scatter on satellite communication links, Proc. IEEE, 81(6), 914-922. 